Mini Review

\title{
AVIAN INFLUENZA A VIRUS AND NEWCASTLE DISEASE VIRUS MONO- AND CO-INFECTIONS IN BIRDS
}

\author{
Iv. Zarkov* \\ Department of Microbiology, Infectious and Parasitic diseases, Faculty of Veterinary Medicine, \\ Trakia University, Stara Zagora, Bulgaria
}

\begin{abstract}
The main features of avian influenza viruses (AIV) and Newcastle disease virus (APMV-1), the possibilities for isolation and identification in laboratory conditions, methods of diagnostics, main hosts, clinical signs and virus shedding are reviewed in chronological order. The other part of the review explains the mechanisms and interactions in cases of co-infection of AIV and APMV-1, either between them or with other pathogens in various indicator systems - cell cultures, chick embryos or birds. The emphasis is placed on quantitative data on the virus present mainly in the first ten days following experimental infection of birds, the periods of virus carrier ship and shedding, clinical signs, pathological changes, diagnostic challenges.
\end{abstract}

Kay words: birds, influenza A virus, Newcastle disease virus, Co-infections.

\section{INTRODUCTION}

Depending on the number of microbial species involved in infection, the latter are classified as mono infections and mixed infections (coinfection). Mono infections are caused by one agent only, while co-infections - by more than one. Most commonly, co-infections occur in intestinal tract and airways. In case of mixed infection, two categories of disease are distinguished:

- Diseases, whose clinical signs could be reproduced with one agent regardless of the presence of another;

- Diseases, in which two or more microbial agents are necessary to induced disease. Often, the effect is multiplied when two or more agents are present as compared to the independent effect of each of them (synergism).

The interaction in case of viral infection is at the cell level. In these instances, co-infection includes simultaneous infection of one cell by two or more viruses. In cases when viruses possess equal cellular receptors, one virus or its components impede the replication of the other virus (es) and the spread of infection. This phenomenon is known as interference.

\footnotetext{
*Correspondence to: Ivan Zarkov, Department of Microbiology, Infectious and Parasitic diseases, Faculty of Veterinary Medicine, Trakia University, Stara Zagora, Bulgaria, E-mail: ivan_zarkov@abv.bg
}

\section{General information about avian influenza viruses (AIV) and AIV mono infections}

Avian influenza viruses (AIV) belong to the family Orthomyxoviridae, genus Influenza $A$ virus. They possess negative-sense singlestrand segmented RNA. The segmented genome is the cause for frequent genetic changes - mutations and recombinations. The most appropriate method for isolation of viruses in laboratory conditions is in 9-11-days old chick embryos (CE) from cloacal or oropharyngeal samples of infected birds, as well as from trachea, lung, air sacs, intestines, spleen, kidneys, brain, heart from dead ones (1). The viruses are cultivated in cell cultured (mainly MDCK) although less easily.

The genus (type) affiliation of viruses is determined by detection of group-specific antigens (from nucleoprotein and M protein. Group-specific antigens are detected in immunodiffusion (ID) test, ELISA, real-time reverse-transcription polymerase chain reaction (rRT-PCR). Subtype of viruses is determined on the basis of surface glycoproteins - haemagglutinins $(\mathrm{H})$ and neuraminidases $(\mathrm{N})$. In birds, 144 subtypes are known arising from the combination of $16 \mathrm{H}-$ and $9 \mathrm{~N}$ - types. The adsorption on cell receptors occurs after activation of viral $\mathrm{H}$ (H0) obtained after its cleavage into $\mathrm{H} 1$ and $\mathrm{H} 2$. Subtypes are detected in haemagglutinin inhibition (HI) test for determination of the $\mathrm{H}$ 
type, neuraminidase inhibition (NI) test for determination of the $\mathrm{N}$ type, rRT-PCR with subtype-specific primers and probes, sequence and phylogenetic analysis. The antibodies in birds are detected via ID, HI, ELISA (1).

In birds, two AIV types are known with respect to their pathogenicity: highly pathogenic (HPAIV) and low-pathogenic AIV (LPAIV). More commonly, infections in birds are caused by LPAIV strains. Avian influenza viruses with all haemagglutinins types could be from the LPAIV type. Strains with H5 and H7 could mutate into HPAIV. They are designated by the highly pathogenic notifiable avian influenza (HPNAI). The difference between LPAIV and HPAIV is in the amino acid sequence at the $\mathrm{H}(\mathrm{H} 0)$ cleavage site into $\mathrm{H} 1$ and $\mathrm{H} 2$ (2). Glycoproteins with three or more basic amino acids (arginine " $R$ " and lysine "K") at the H0 cleavage site recognised by the precursor protein furin define the strains as HPAIV $(3,4)$. An example of amino acid sequence in HPAIV is PQRES RRKK / GLF. The cleavage of $\mathrm{H} 0$ into $\mathrm{H} 1$ and $\mathrm{H} 2$ in LPAIV depends on trypsin and trypsin-like enzymes, whereas in HPAIV it occurs without trypsin or trypsin-like enzymes.

Apart the determination of amino acid sequence of $\mathrm{H} 1$ and $\mathrm{H} 2$ glycoproteins, pathogenicity could be evaluated with 10 susceptible experimental 4-8-week-old chickens, inoculated intravenously with $0.1 \mathrm{ml}$ $1 / 10$ diluted viral isolate in CE, observed over 10 days. The result is detected as intravenous pathogenicity index (IVPI). All healthy birds are scored with 0 , the diseased ones -1 point, severely ill -2 points and dead -3 points. The result is the sum of all points from all birds for 10 days, divided to the number of infected birds. HPAIV and HPNAI have IVPI values over 1.2 (maximum score 3.0, when all chickens die) or provoke death in at least $75 \%$ of infected birds. There are exceptions from the rule. The strains H10N5 and H10N4 possess IVPI $>1.2$, but do not cause disease when applied intranasally. The H7N3 strains isolated in Chile and Canada are HPAIV, but do not have amino acid configuration for HPAIV at H0 cleavage site into H1 and H2 (1). Domestic and wild birds are susceptible to all AIV. Wild waterfowl are natural AIV hosts and during migration spread them at huge distances and to novel hosts. From the 8,600 known avian species, isolates are so far discovered only in $1.2 \%$ (5). They belong to 12 orders - Gaviiformes, Podicepediformes, Procellariiformes, Pelecaniformes, Ciconiiformes, Anseriformes, Galliformes, Gruiformes, Columbiformes, Charadriiformes,
Piciformes, Passeriformes. Among the 12 orders, AIV isolates have benn obtained from 106 avian species (6), and their distribution is irregular both within orders and families, and within species as well.

Wild waterfowl are the main source of infection for domestic poultry (7). From the latter, most commonly affected are chickens (Gallus domesticus), turkeys (Meleagridis galopava), ducks (Anas spp.), geese (Anser spp.), which spread consequently the virus among them and to other closely related susceptible birds (8).

The clinical signs in birds depend on the species, age, virus type and other external factors. Highly pathogenic avian influenza viruses are characterised with up to $100 \%$ morbidity and mortality rates. Its course could be accompanied with sudden death, with all specific clinical signs or with less signs as well as to be asymptomatic (Pekin ducks). The main clinical signs are nasal discharge, cough, dyspnea, oedema of sinuses or head, inappetance, cyanosis of the skin, comb and wattles, legs; lack of coordination, nervous signs, diarrhoea, drop in egg production in laying birds. Birds infected with LPAIV do not exhibit clinical signs, manifest mild symptoms (respiratory or intestinal) or under certain circumstances (including presence of other infection agents) show signs similar to those after HPAIV (1).

The localisation of HPAIV is in all organs and systems, while that of LPAIV - in the airways and alimentary system, which is important in sampling for laboratory isolation. The LPAIV localisation in birds is in sites with presence of trypsin or trypsin-like enzymes, needed for cleavage of $\mathrm{H}(\mathrm{H} 0)$ into $\mathrm{H} 1$ and $\mathrm{H} 2$. It is also established that the infection with LPAIV depends on the avian host species, the site of penetration into the host, the amount of virus an the viral strain (adaptation of the strain to the host), which vary within a broad range. These data are obtained after investigations on field infections and after experimental infection with monitoring of clinical, pathological changes, the periods of virus carriership and virus shedding, the titre of reisolated virus, antibody response $(7-14)$. In experimental conditions with birds infected with LPAIV subtype H6N2 (the most frequently isolated subtype in Bulgaria), the virus was reisolated in $100 \%$ of infected ducklings until post infection (PI) day 5, until PI day 7 in infected guinea fowl, until 3 PI day 10 in $67 \%$ of infected geese, until PI day 7 in $56 \%$ of infected turkeys and until PI day 5 in 
$33 \%$ of infected chickens. The virus reisolation in ducks continues until the $21^{\text {st }} \mathrm{PI}$ day, in guinea fowl - until PI day 14 , in geese and turkeys - until the $10^{\text {th }}$ PI day and in chickens - until the $5^{\text {th }}$ PI day. Reisolation in all avian species was done from the cloaca and the oropharynx. For some strains, more reisolates and more prolonged reisolation was done from the cloaca, while in others - from the oropharynx. In ducks infected with H6N2, the reisolation was until the $21^{\text {st }}$ day from the cloaca and until the $10^{\text {th }}$ day from the oropharynx, in guinea fowl: until the $14^{\text {th }}$ and $10^{\text {th }}$ day from the cloaca and oropharynx respectively; in geese: until PI days 10 and 5 respectively, in turkeys: PI days 10 and 7; in chickens - until PI days 5 and 3 (15-19).

Birds are not vaccinated against LPAIV. An element of HPAIV control is vaccination with inactivated oil adjuvant vaccine with the same $\mathrm{H}$ and/or $\mathrm{N}$ provoking the disease. It is practiced in some countries and depends on the spread of the virus on the respective territory, economic losses, virus subtype, risk for the population $(20,21)$.

\section{General information for Newcastle disease virus (NDV) and NDV monoinfections}

The Newcastle disease virus (NDV, APMV-1) belongs to order Mononegavirales, family Paramyxoviridae, genus Avulavirus. Avulavirus involves 10 serotypes (APMV 110), the NDV being serotype 1 (22). It possesses negative-sense single-strandsegmented RNA. The hosts are about 200 wild and domestic bird species. Men could be also infected. In pigeons, there is an independent disease entity, namely paramyxovirosis (PPMV-1).

The virus is isolated using samples and methods similar to those described for AIV. The APMV-1 strains are of various virulence (pathogenicity). According to their virulence, 5 APMV-1 groups are distinguished viscerotropic velogenic, neurotropic velogenic (all of them highly virulent), mesogenic (of medium virulence) lentogenic or respiratory (low-virulent) and asymptomatic (23). The virulence is determined by amino acid sequence at the site of F0 protein cleavage (the $\mathrm{F}$ protein is synthesised as a precursor and needs to be divided into two small fragments: F1 and F2 to function properly). When the F2 protein has several basic amino acids arginine (R) and/or lysine (K) at the cleavage site (C-terminus of F2) and phenylalanine at position 117 (the $\mathrm{N}$-terminus of $\mathrm{F} 1$ ) the strain is virulent $(24,25,26)$.
The isolation is mainly in CE, rarely in cell cultures, and the identification of the virus as APMV 1 is done via HI assay (gives crossreaction with APMV-3 and APMV-7), reversetranscription polymerase chain reaction (RTPCR) of F gene fragments (the M gene is not highly conservative and could give false results), rRT-PCR. The problems with molecular diagnostic techniques are associated to genetic differences of strains (presence of class I and class I viruses, 6 genogroups, with subgroups to genogroup 3, 4 and 5) (27). Therefore, multiplex RT-PCR or rRT- PCR with primers of both classes should be preferably utilised.

The pathogenicity of strains is evaluated after infection of day-old experimental seronegative or pathogenic-free (SPF) chickens or through determination of amino acid sequence at the site of F0 cleavage. When experimental chickens are used, an intracerebral pathogenicity index (ICPI) is determined with 8-day observation of infected birds. Those without clinical signs are scored with 0 points, the diseased and dead ones - with 1 and 2 points respectively. Velogenic strains have scores >1.5; mesogenic - from 0.7 to 1.5 and lentogenic $-<0.7$. When pathogenicity of strains is determined via amino acid sequences, the latter are determined at the C-terminus of the F2 protein between the 112 th and $116^{\text {th }}$ amino acid and the $117^{\text {th }}$ amino acid at the Nterminus of the $\mathrm{F} 1$ protein. Virulent strains have a configuration $(112 \mathrm{G} / \mathrm{K}-\mathrm{R}-\mathrm{Q} / \mathrm{K} / \mathrm{R}-\mathrm{K} / \mathrm{R}-$ $\mathrm{R}$ 116) at the $\mathrm{C}$-terminus of the $\mathrm{F} 2$ protein and phenylalanine as $117^{\text {th }}$ amino acid at the $\mathrm{N}$ terminus of $\mathrm{F} 1$. A strain should possess at least three arginine (R) and/or lysine (K) bases (28). Serological tests for detection of antibodies against avian APMV-1 are the HI test, ELISA, virus neutralisation test.

The sensitivity of birds to APMV-1 (no matter the virulence for chickens) varies and depends on a number of factors as the viral strain, host species, external factors (temperature, season, stress etc.) The infection of birds with virulent strains results in high death rates and specific clinical signs depending on the virulence extent (velogenic, mesogenic). Chickens and hens infected with velogenic-viscerotropic strains exhibit apathy, anorexia, emaciation, prostration, respiratory signs, periocular oedema, greenish diarrhoea, nervous signs (corticoids, opisthotonus), drop in egg production and up to $100 \%$ mortality. Velogenic-neurotropic strains provoke nervous and respiratory signs and 50\% - 90\% death rates. Mesogenic strains induce nervous and respiratory signs and mortality in small chicks. 
Lentogenic strains are located in the airways and the alimentary system due to their dependency upon the presence of protease (trypsin) and protease-like enzymes needed to cleave F0 (similar to LPAIV and H0). They provoke mild respiratory signs or no signs (29).

Vaccination as a method of control of Newcastle disease in birds is widely used. It usually protects the birds from the appearance of clinical signs, development of disease and death (30). The immunity against the disease is mainly due to antibodies raised against the two surface viral glycoprotein peplomers - F and $\mathrm{HN}$ proteins. The use of live lentogenic APMV-1 (most commonly Hitchner B1 and La Sota) as vaccinal strains is common on a global scale. It has the advantage of being cheap, offers various routes of application, provokes general and local immunity, rapid onset of cellular and humoral immunity, possibility for transmission of the vaccinal virus from one bird to another within the herd. The vaccination protocols in the EC are specified $(31,32)$.

The used lentogenic APMV-1 strains as live vaccines for protection from a virulent virus cause a mild respiratory distress in SPF chickens under experimental conditions (strains with ICPI up to $0.4-0.5$ are allowed in the EC). Nevertheless these are the most widely used NDV strains for vaccination purposes (23). They are applied with drinking water, as an aerosol, via intranasal and conjunctival routes. Inactivated vaccines are safe but their application is more labourous (only parenterally) as well as more expensive (32).

\section{Data for APMV-1 and/or AIV co- infections in birds.}

There are reports with co-infections with two different viruses, as well as with bacteria and viruses. They have been performed in cell cultures, chick embryos and e They have been performed in cell cultures, chick embryos and experimental birds.

\section{A. Co-infections between bacteria and either APMV-1 or AIV.}

Charles at al. (33) conducted three experiments, infecting 4-week-old turkey poults with Pasteurella anatipestifer followed by vaccination with APMV-1, with a virulent APMV-1 and superinfection with Pasteurella anatipestifer and with Pasteurella anatipestifer only. There was no difference in clinical signs and pathological changes in birds inoculated with vaccinal APMV-1 strain and Pasteurella anatipestifer and with Pasteurella anatipestifer only. A difference was noted in the course of disease, gross anatomy and histopathological changes after infection with virulent APMV-1 strain and superinfection with Pasteurella anatipestifer.

Ornithobacterium rhinotracheale (ORT) is the etiological agent causing respiratory infection in birds (airsacculitis and pneumonia). The clinical signs depend on the virulence of strain, host immune status and the presence of other infectious agents (34). The studies in birds infected with H9N2 AIV demonstrated that the strain induced respiratory distress $(35,36)$. In spontaneous progressive pneumonia in broilers and laying hens in China, morbidity rate attained $70 \%$ and mortality - 30\%. The experiments performed with both isolates (ORT and influenza virus H9N2) confirmed the clinical signs and death rate in spontaneous cases, whereas monoinfections with each of etiological agents did not provide evidence for such changes. The authors concluded that economic losses and mortality incurred by ORT were high, when the avian influenza virus H9N2 was also involved (37).

Stipkovits et al., 2012 (38) investigated coinfection with Mycoplasma gallisepticum and a LPAIV strain H3N8 (A/mallard/Hungary/ 19616/07) in chickens. The authors monitored the presence of clinical signs of disease and antibody levels against Mycoplasma gallisepticum and LPAIV strain H3N8. The results were compared with monoinfections with either Mycoplasma gallisepticum or c LPAIV H3N8. Clinical signs were proved during Mycoplasma gallisepticum monoinfection and co-infection with Mycoplasma gallisepticum and LPAIV strain H3N8, with more severe signs in the latter case. The antibody response against Mycoplasma gallisepticum was considerably reduced in co-infected birds. The authors concluded that LPAIV strain H3N8 enhanced the pathogenicity of Mycoplasma gallisepticum.

\section{B. Co-infections with two viruses}

- In cell cultures and chick embryos

As early as in 1945, Burnet (39) proved that after infecting cells with both viruses (AIV and APMV-1), the erythrocytes remained refractory to one of viruses in the HI test.

Florman, 1948 (40) demonstrated that after infection with APMV-1, CE were not susceptible after repeated (after $24 \mathrm{~h}$ ) infection with AIV even at high doses. Bang, 1949 (41) found out that AIV infection followed by 
challenge with low doses of a virulent APMV1 strain has no lethal effect in embryos. Later, Shortridge and King, 1983 (42) proved that AIV were preferentially detected as compared to APMV-1 after infection with several subtypes of AIV (H4N6, H5N3, H7N2, H9N2, H12N5) and co-infection with APMV-1. The factors influencing the results were attributed by the authors to the different multiplication performance of both viruses and their intrinsic interference. The results of Liu et al., 2003 (43) indicated that AIV (with H9) interfered strongly with APMV-1 replication in allantoic fluid of infected CE and that the interference was influenced by the presence of serum with antibodies. Ge and co-authors, 2012 (44) investigated co-infection with two AIV (F98 and H5N1) and two APMV-1 (LaSota and F48E8) in CE via real-time RT-PCR. The authors tested variants of simultaneous infection, preliminary with AIV followed by APMV-1 and vice versa, with the second virus challenge occurring after 12 or 24 hours. In their experiments, the authors proved that when different AIV and APMV-1 doses were applied at the same time, AIV had a negative effect on APMV-1 replication. APMV-1 did not influence the replication of AIV. The extent of influence on APMV-1 after challenge with equal amounts of both viruses depended on the time of inoculation of the second viral agent and AIV virulence. If CE are infected first with APMV-1, AIV replication could be altered.

The review of data makes clear that in CE coinfected with AIV and APMV-1 exhibited interference as revealed by classical and modern methods of investigation. When AIV is applied before or together with APMV-1, interference occurs. The results are dependent on the dose (amount) of the virus, the time of challenge with the second virus, the virulence of strains and the presence of antibodies.

\section{- In birds.}

Co-infection with two viruses is frequently seen in field cases, but related information is scarce. Co-infection could make the disease course more severe, mixed clinical signs could be established, death rate could be higher and pathological changes other that the usual one could be present (45). Furthermore, coinfection with two viruses could lead to altered tropism of viruses and to misleading diagnosis $(38,42)$.

\section{With low pathogenic AIV and APMV-1 strains.}

The infection of a host with one of viruses in most cases has an effect on infection with the other. This is due to the circumstance that AIV and APMV-1 have identical receptors and the same site of localisation in the body (airways and gastrointestinal tract) due to their dependency on trypsin and trypsin-like enzymes. There, they compete for target cells. As a result, the co-infection (depending on the host bird species) could result in altered production of progeny virus with effects on clinical signs, immune response which could impede the detection in avian flocks (46). Examples are the studies of El Zowalaty et al., 2011; Costa-Hurtado et al., 2014; França et al., 2014 and Sajid Umar et al., 2015 (47 - 50).

El Zowalaty et al (2011) proved that the presence of mixed APMV-1 and AIV infection (detected by RT-PCR) in cloacal sample of free living ducks could inhibit AIV replication and yield negative results in attempts for AIV isolation in $\mathrm{CE}$ (false negative results). The AIV isolation is possible when cloacal samples are processed with sera with antibodies against APMV-1.

Costa-Hurtado et al. (2014) infected chickens and turkeys with lentogenic APMV-1 LaSota strain and LPAIV subtype H7N2 independently, simultaneously and consequently. In chickens clinical signs of disease were not shown neither in birds with monoinfection, neither in co-infected ones. There were differences only in virus shedding, with lower titers of the second virus on PI days 2 and 3 in co-infections, proof of altered dynamics of its replication. The turkeys infected with LPAIV only and co-infected with a lentogenic AMPV-1showed mild signs of disease. They exhibited greater differences compared to chickens associated to lower number of birds with infection and lower titres.

França et al. (2014) conducted one experiment with one-month-old mallard infected nasally simultaneously with a lentogenic APMV-1 and a LPAIV (H3N8) as well as a second experiment with LPAIV (H3N8) in which it was applied 2 and 5 days after the lentogenic APMV-1. According to the results, all birds were infected with both viruses as confirmed from virus shedding and serological response to both pathogens. There was no statistically significant difference in studied cloacal samples in favour of LPAIV. The authors concluded that co-infection did not have an effect on LPAIV replication in mallards.

In Egyptian fayoumi chickens, Sajid Umar et al. (2015) obtained comparable results as those of Costa-Hurtado et al. (2014). One part of the birds were nasally infected with each of the 
viruses, and another part - simultaneously with lentogenic APMV-1 and LPAIV H9N2. Over three days after the co-infection, lower titres and less amount of both viruses were detected compared to monoinfection. In the days that followed, the amount of LPAIV H9N2 in the oropharynx increased, but that of APMV-1 remained low.

\section{With low pathogenic AIV or APMV-1 strains and another virus.}

Experimental studies were carried out in birds in which a live vaccine with infectious bronchitis virus was applied (widely used in poultry industry) and then, they were challenged with H9N2 (51). The co-infection resulted in increased shedding of $\mathrm{H} 9 \mathrm{~N} 2$, more severe clinical signs, increased mortality rate and pathological changes.

El-Yuguda et al. (2007, 2014) (52, 53) performed experiments with two bird species (guinea fowl and chickens). In two experimental designs with guinea fowl they investigated the immune response after vaccination with live vaccine of infectious bursal disease virus (IBDV) followed by vaccination with lentogenic La Sota APMV-1 strain 7 days later; while the second design included infection of birds with a pathogenic IBDV strain and vaccination with lentogenic La Sota APMV-1 strain 7 days later. In chickens, simultaneous vaccination with IBDV and La Sota APMV-1 was done in one of trials, whereas in the second one IBDV challenge was later followed by vaccination with a lentogenic APMV-1 La Sota strain. The results were compared to monoinfections. The authors reported disturbances in humoral immune response in both bird species in comparison to that against the vaccinal APMV-1, when the latter was applied at a later stage. It was raised both after challenge with vaccinal as well as pathogenic IBDV. When both vaccinal viruses were applied at the same time in chickens, no changes in humoral immune response were observed. The cause for the altered humoral immune response according to the authors was due to the necrosis in lymphoid organs induced by the IBDV.

\section{With highly pathogenic AIV and APMV-1 strains.}

Chickens inoculated with H9N2 and 7 days later with a velogenic APMV-1 strain resulted in higher mortality with faster onset of the fatal outcome, more severe clinical disease and more severe pathological changes compared to viral monoinfections (54).
In experiments with APMV-1 and HPAIV strains, Costa-Hurtado et al., 2015 (55) demonstrated that a preliminary infection of chickens with a virulent APMV-1 (strain $\mathrm{CA} / 2002$ ), but not with lentogenic strain ( $\mathrm{La}$ Sota) reduced the replication of HPAIV (H5N2) applied two days later at high doses $\left(10^{6.9}\right.$ EID $\left.{ }_{50}\right)$, although the mortality rate was preserved. The inoculation with a less virulent APMV-1 strain (mesogenic Pigeon/1984) and HPAIV (H5N2 or H7N3) applied some time apart (after 3 days) and at lower doses (10 ${ }^{5.3-}$ ${ }^{5.5}$ EID ${ }_{50}$ ) also decreased HPAIV replication but increased survival rates. The authors concluded that replication, morbidity and mortality caused by the HPAIV applied after a virulent APMV-1 were reduced as a result of interference. It also depended on the viral titres, the virulence of the initially applied virus (APMV-1) and the time for application of the second one (HPAIV).

Pantin-Jackwood et al. (2015) (56) performed experimental intraocular and intranasal infection of a group of domestic ducks with a velogenic APMV-1 and a LPAIV (H7N8), a second group was challenged with a velogenic APMV-1 and a HPAIV (H5N1) and other groups were with monoinfections caused by each of these viruses. Co-infections were conducted either simultaneously or two days apart. The clinical signs, virus shedding, transmission to susceptible birds in infected groups were followed out. Co-infections with velogenic APMV-1 and LPAIV did not result in clinically manifested disease, but the shedding of APMV-1 declined during the first four post infection days. Co-infection did not influence the number of birds shedding LPAIV, but during the first 2 days after the infection, a greater amount of the virus was detected in comparison to LPAIV monoinfection. The ducks infected simultaneously with a velogenic APMV-1 and HPAIV exhibited a shorter period of survival than those challenged with a velogenic APMV1 two days prior to the HPAIV. Furthermore, the transmission to susceptible birds was reduced. The observed changes were attributed to the interference due to infection with more than one virus, which reflected on virus replication, modified the pathogenesis of the disease and transmission of the virus to susceptible bird hosts.

\section{CONCLUSIONS}

Birds are often infected with more than one infectious agent. Co-infections are also observed during vaccination with one or more live vaccines at the background of a 
spontaneous infection. On a global scale, birds are actively and repeatedly vaccinated with live lentogenic vaccine of various APMV-1 strains while other infections, in particular with AIV are frequently encountered. The interest to co-infections of birds with APMV-1 and AIV is due to the fact that they compete for the same receptors in susceptible cells. Comparative data about clinical, pathological, diagnostic data in birds with mono- and coinfections showed that they differed substantially when a second infectious agent was involved. Also, co-infection was related to altered tissue tropism, virus replication, different period of virus production and realisation, altered immune response. Experimentally reproduced co-infections in different indicator biological systems (cell cultures, chick embryos, birds) demonstrate that the time of infection with the second pathogen, latency, dose, virulence and biological properties of pathogens were important.

\section{The publication is a scientific project №1/2016,VMF}

\section{REFERENCES}

1. Anonymous. Avian influenza. Version adopted by the World Assembly of Delegates of the OIE in May 2015. OIE Terrestrial Manual. C H A P T E R 2.3.4 : 1- 23, 2015.

2. Rott, R., Reinacher, M., Orlich, M. And Klenk, H. D. Cleavability of hemagglutinin determines spread of avian influenza viruses in the chorioallantoic membrane of chicken embryo. Archives of Virology, 65, 2: 123 - 133, 1980.

3. Grober, S. A., Vey, M., Angliker, H., Shaw, E.,. Thomas, G., Roberts, C., Klenk, H. D and Garten, W. Influenza virus hemagglutinin with multibasic cleavage site is activated by furin, a subtilisin-like endoprotease. EMBO Journal, 11: 2407 2414, 1992.

4. Suarez, D.L. Influenza A virus. In: Avian Influenza. Edited by Swayne D.E., Blackwell Publishing. Ames, Iowa, USA, 3 - 22, 2008.

5. Stallknes, D. E. Ecology and Epidemiology of avian influenza viruses in Wild Bird Population : Waterfowl, shorebirds, Pelicans, Cormorants. Ets. Proseedings of Fourth International Symposium on Avian Influenca, Athens, Georgia, U. S. Animal Health Association, Georgia Centre for Continuing Edication, The University of Gorgia, eds. Swayne, D.E., Slemons, R.D., Rose Printing Company, Tallahassee, FL, May 29-31 : 61 - 69, 1997.
6. Bjötrn, O., Munster, V., Wallensten, A., Waldenström, J., Osterhaus, A. \& Fouchier, R. Global patterns of influenza A virus in wild birds. Science, $312: 384$ - 388, 2006.

7. Swayne, D. E., Slemons, R. D. Using mean infectious dose of High- and Lowpathogenicity avianinfluenza viruses originating from wild duck and poultry as one measure of infectivity and adaptation to poultry. Avian diseases, 52: 455 - 460, 2008.

8. Alexander, D. J. A review of avian influenza in different bird species. Veterinary Microbiology, $74: 3$ - 13, 2000.

9. Tumpey, T. M., Kapczynski, D. R. and Swayne, D. E. Comparative susceptibility of chickens and turkeys to avian influenza A H7N2 virus infection and protective efficacy of a commercial avian influenza H7N2 virus vaccine. Avian Diseases, 48 : 167 - 176, 2004.

10.Zarkov, I.S. Experimental studies on some biological properties of Influenza A virus and particularities of infection in birds. DSc thesis, Sofia, 1- 365, 2007.

11.PillaI, S.P.S., Pantin-Jackwood, M., Suarez, D. L., Saif, Y.M.\& Lee, C.W. Pathobiological characterization of lowpathogenicity h5 avian influenza viruses of diverse origins in chickens, ducks and turkeys. Archiv Virology, 1 - 13, 2010.

12.Otsuki, K., Kawaoka, Y., Nakamura, T.and Tsubokura, M. Pathogenicity for chickens of avian influenza viruses inoculated from whistling swans and a black-tailed gull in Japan. Avian Diseases, 26, 1: 314 - 320, 1982.

13.Wood, J. M., Webster, R. C. \& Nettles,V. F. Host range of A /chicken/ Pennsylvania /83/H5N2/ influenza virus. Avian diseases, 29: 198 - 207, 1985.

14.Laudert, E., Halvorson, D., Sivanandan, V. and Shaus D. Comparative evaluation of tissue tropism characteristics in turkeys and mallard ducks after intravenous inoculation of type A influenza viruses. Avian Diseases, 37: 773 - 780, 1993.

15.Zarkov, Iv. Shedding of the avian Influenza A H6N2 subtype virus in ducklings, turkey poults and chickens experimentally infected. Revue Medicine Veterinare, 159, 7: 408 - 412, 2008.

16.Zarkov, Iv., Koev, K., and Dinev, Iv. Shedding of the avian Influenza A H6N2 subtype virus isolate in Numida meleagris, Trakia Journal of Sciences, 1: 59 - 64, 2014.

17.Zarkov, Iv., Marutsov, P. and Raenkova, E. Period of shedding of the avian influenza A H6N2 subtype virus isolate in young 
domestic fowl, Trakia Journal of Sciences, Vol. 9, No 1: 71-77, 2011.

18.Zarkov, Iv., and Dinev, Iv. Clinical and morphological studies of ducklings experimentally infected with a H6N2 strain isolate of low pathogen avian influenza A virus. Revue Méd. Vét., 163, 2: 64 - 69, 2012.

19.Dimitrov, K.M., Zarkov, Iv., Dinev, Iv, Goujgoulova, G., Miller, P.J., and. Suarez, D.L. Histopathological characterization and shedding dynamics of LPAI H6N2 in Guinea fowls (Numida meleagris) infected experimentally. $\quad 9^{\text {th }} \quad$ International symposium on Avian Influenza. The University of Georgia, Athens GA, USA, 12-15 april, 2015.

20.Swayne, D. E., Pavade, G., Hamilton, K., Vallat, B., and Miyagishima, K. Assessment of national strategies for control of high-pathogenicity avian influenza and low-pathogenicity notifiable avian influenza in poultry, with emphasis on vaccines and vaccination. Rev. Scien. Tech., 30 : 839 - 870, 2011.

21.Spackman, E., \& Swayne, D. E. Vaccination of gallinaceous poultry for H5N1 highly pathogenic avian influenza: current questions and new technology. Virus Res., 178:121 - 132, 2013. doi: 10.1016/j.virusres.2013.03.004.

22.Miller, P. J., Afonso, C.L., Spackman, E., Scott, M. A., Pedersen, J. C., Senne, D. A., Brown, J. D., Fuller, C. M., Uhart, M. M., Karesh, W. B., Brown, I. H., Alexander, D. J. \& Swayne, D. E.. Evidence for a New Avian Paramyxovirus Serotype-10 Detected in Rockhopper Penguins from the Falkland Islands. J. Virol., 84 (21) : 11496 - 11504 , 2010.

23. Alexander, D. J., and Senne, D. A. Newcastle disease. In: Diseases of Poultry. $12^{\text {th }}$ edition. Edited by Saif Y.M., Glisson J.R., Mc Dougald L.R., Nolan, L.K., Swayne D. E. Ames, Iowa, USA: Blackwell Publishing; 75 - 100, 2008.

24. Kohama, T., Garten, W., and Klenk, HansDieter. Changes in conformation and charge paralleling proteolytic activation of Newcastle disease virus glycoproteins. Virology, Vol. 111, Issue 2, : 364 - 376, 1981.

25.Miller, P. J., Estevez, C., Yu, Q., Suarez, D.L., and King, D.J. Comparison of viral shedding following vaccination with inactivated and live Newcastle disease vaccines formulated with wild-type and recombinant viruses. Avian Dis., 53 (1) : 39 - 49, 2009.
26.Panda, A., Huang, Z., Elankumaran, S., Rockemann, D.D., and Samal, S.K. Role of fusion protein cleavage site in the virulence of Newcastle disease virus. Microb. Pathog., 36 (1) : 1 - 10, 2004.

27.Aldous, E. W., Mynn, J. K., Banks, J. \& Alexander, D. J. A molecular epidemiological study of avian paramyxovirus type 1 (Newcastle disease virus) isolates by phylogenetic analysis of a partial nucleotide sequence of the fusion protein gene. Avian Pathol., 32 (3) : 239 256, 2003.

28.Choi, K. S., Lee, E. K., Jeon, W. J. \& Kwon, J. H. Antigenic and immunogenic investigation of the virulence motif of the Newcastle disease virus fusion protein. $J$. Vet. Sci., 11 (3) : 205 - 211, 2010.

29.McFerran, J. B. \& Mc Cracken, R.M. Newcastle disease. In: Newcastle Disease (D. J Alexander editor). KluwerAcademic Publishers, Boston, MA.: 161 - 183, 1988.

30.Parede, L., Young, P.L.The pathogenesis of velogenic Newcastle disease virus infection of chickens of different ages and different levels of immunity. Avian Dis., 34 (4) : 803-808, 1990.

31.European Commission. Commission Decision of 8 February 1993 laying down the criteria for vaccines to be used against Newcastle disease in the context of routine vaccination programmes (93/152/EEC): Official Journal of the European Communities L 59, 35 (Decision as amended by Decision 2010/633/EC: Official Journal of the European Union, L 279, 33), 1993.

32.Anonymous. Newcastle disease. Version adopted by the World Assembly of Delegates of the OIE in May 2012. OIE Terrestrial Manual, C H A P T E R 2.3.14: $1-19,2012$.

33. Charles, S. D., Nagaraja, K.V., Halvorson, D.A., and Barnes, D.M. Influence of Newcastle disease virus on the severity of Pasteurella anatipestifer infection in turkeys. Research in Veterinary Science, Volume 55, Issue 2 : 209 - 214, 1993.

34.Van Empel, P., and Hafez, H. Ornithobacterium rhinotracheale: a review. Avian Pathol., 28 : 217 - 227, 1999.

35.Swayne, D. E., Senne, D.A., Beard, C.W. Isolation and identification of avian pathogens. 4th edition. American Association of Avian Pathology, Pennsylvania, USA; 1998.

36.Haghighat-Jahromi, M., Asasi, K., Nili, H., Dadras, H., and Shooshtari, A.H. Coinfection of avian influenza virus (H9N2 
subtype) with infectious bronchitis live vaccine. Arch.Virol., 153 : 651 -655, 2008.

37.Pan, Q., Liu, A., Zhang, F., Ling, Y., Ou, C., Hou, N. and He, C. Co-infection of broilers with Ornithobacterium rhinotracheale and H9N2 avian influenza virus. BMC Veterinary Research, 8 : 104, 2012, doi:10.1186/1746-6148-8-104.

38.Stipkovits, L., Egyed, L., Palfi, V., Beres, A., Pitlik, E., Somogyi, M., Szathmary, S., \& Denes, B. Effect of low-pathogenicity influenza virus H3N8 infection on Mycoplasma gallisepticum infection of chickens. Avian Pathology, Volume 41, Issue $1: 51$ - 57, 2012.

39.Burnet, F.M. Experiments on the elution of Newcastle disease virus and influenza virus from fowl red cells. Aust. J. Exp. Biol. Med. Sci., 23 : 180 - 183, 1945.

40.Florman, A.L. Some alterations in chicken erythrocytes which follow treatment with influenza and Newcastle disease virus. $J$. Bacteriol., 55 : 183 - 196, 1948.

41.Bang, F. Cell blockade in Newcastle disease of chickens and chicken embryos. $J$. Exp. Med., 89 : 141. 10.1084/jem.89.2.141, 1949.

42.Shortridge, K.F., and King, A,P. Cocultivation of avian orthomyxoviruses and paramyxoviruses in embryonated eggs: implications for surveillance studies. Appl Environ Microbiol., 45 : 463 - 467, 1983.

43.Liu, W., Ding, W., Kong, J., Wang, H., Hu, S., He, H., Zhang, R.and Liu X. The interference in the virus propagation in chicken embryo and in the HI test between the newcastle disease virus and the H9 subtype influenza virus. Chinese Poultry Science, 7: 3, 2003.

44.Ge, S., Zheng, D., Zhao, Y., Liu, H., Liu, W., Sun, Q., Li, J., Yu, S., Zuo, Y., Han, X., Li, Lin., Yan, L., Wang, Y., Liu, X., and Wang Z. Evaluating viral interference between Influenza virus and Newcastle disease virus using real-time reverse transcription-polymerase chain reaction in chicken eggs. Virology Journal, 9 : 128, 2012. DOI: $10.1186 / 1743-422 X-9-128$.

45.Halvorson, D. A. Control of low pathogenicity avian influenza. In: Avian influenza. Edited by Swayne DE.: Blackwell Publishing, Ames Iova, USA : 513-536, 2008.

46. Woolcock, P. R. Avian influenza virus isolation and propagation in chicken eggs. In E. Spackman, (Ed.). Avian Influenza Virus lsted. : 35-46. Totowa, NJ: Humana Press, 2008.

47.El Zowalaty, M.E., Chander, Y., Redig, P.T., Abd el Latif, H.K., El Sayed. M.A., and Goyal, S, M. Selective isolation of Avian influenza virus (AIV) from cloacal samples containing AIV and Newcastle disease virus. J. Vet. Diagn. Invest., 23 : $330-332,2011$

48.Costa-Hurtado, M., Afonso, C. L., Miller, P. J., Spackman, E., Kapczynski, D. R., Swayne, D. E., Shepherd, E., Smith, D., Zsak, A. and Pantin-Jackwood, M. Virus interference between $\mathrm{H} 7 \mathrm{~N} 2$ low pathogenic avian influenza virus and lentogenic Newcastle disease virus in experimental coinfections in chickens and turkeys. Vet. Res. 45 (1) : 1. Published online 2014, Jan 6, 2014, doi: 10.1186/1297-9716-45-1, PMCID: PMC3890543.

49.França, M., Howerth, E. W. , Carter, D., Byas, A., Poulson, R., Afonso, C. L. \& Stallknecht, D. E. Co-infection of mallards with low-virulence Newcastle disease virus and low-pathogenic avian influenza virus. Avian Pathology, 43, 1: 96 - 104, 2014.

50. Umar, S., Azeem, T., Abid, S. A., Mushtaq, A., Aqil, K., Qayyum, M.R., and Rehman, A. Effect of lentogenic Newcastle disease virus (Lasota) on low pathogenic avian influenza vrus (H9N2) infection in fayoumi chicken. Journal of Avian Research, 1 (1) : 1 - 4, 2015.

51.França, M., Howerth, E. W. , Carter, D., Byas, A., Poulson, R., Afonso, C. L. \& Stallknecht, D. E. Co-infection of mallards with low-virulence Newcastle disease virus and low-pathogenic avian influenza virus. Avian Pathology, 43, 1: 96 - 104, 2014.

52.Haghighat-Jahromi, M., Asasi, K., Nili, H., Dadras, H., and Shooshtari, A.H. Coinfection of avian influenza virus (H9N2 subtype) with infectious bronchitis live vaccine. Arch. Virol., 153 : 651-655, 2008. doi: 10.1007/s00705-008-0033-x.

53.El-Yuguda, A. D, Wachida, N. and Baba, S. $\mathrm{S}$. Interference of Infectious Bursal Diseases (IBD) Virus and Vaccine with the Immune Responses of Guinea Fowls to Newcastle Disease Lasota Vaccination. African Journal of Biomedical Research, Vol. 10: 189 - 192, 2007.

54.El-Yuguda, A. D., Baba, S. S., \& Geidam, Y.A. Specific antibody response of village chickens to single or combined Newcastle disease and infectious bursal disease vaccines. J. Adv. Vet. Anim. Res. 1(1): 16 20, 2014

55.Lee, Sung-Min, Cho, Eun-Sang, Choi, BoHyun, Son, Hwa-Young. Clinical and pathological studies on co-infection of lowpathogenic avian influenza virus and Newcastle disease virus in the chicken. 
Korean Journal of Veterinary Service, Volume 36, Issue 3, : 163 - 169, 2013.

56.Costa-Hurtado, M., Claudio, L., A., Miller, P. J., Shepherd, E., Cha, R. M., Smith, D., Spackman, E., Kapczynski, D. R., Suarez, D. L., Swayne, D. E. and PantinJackwood, M. J. Previous infection with virulent strains of Newcastle disease virus reduces highly pathogenic avian influenza virus replication, disease, and mortality in chickens. Vet. Res.; 46 (1) : 97, 2015.
Published online 2015 Sep 23. doi: 10.1186/s13567-015-0237-5.

57.Pantin-Jackwood, M. J., Costa-Hurtado, M., Miller, P. J., Afonso, C. L., Spackman, E., Kapczynski, D. R., Shepherd, E., Smith, D., \& Swayne, D. E. Experimental coinfections of domestic ducks with a virulent Newcastle disease virus and low or highly pathogenic avian influenza viruses. Veterinary Microbiology, Volume 177, Issues 1-2: 7 - 17, 2015. 